\title{
Biodiesel Production from Ceiba pentandra Seed Oil Using CaO Derived from Snail Shell as Catalyst
}

\author{
Chika Muhammad, Zaliha Usman, Francis Agada* \\ Department of Pure and Applied Chemistry, Faculty of Science, Usmanu Danfodiyo University, Sokoto, Nigeria
}

Email address:

francisagada49@gmail.com (F. Agada)

${ }^{*}$ Corresponding author

\section{To cite this article:}

Chika Muhammad, Zaliha Usman, Francis Agada. Biodiesel Production from Ceiba pentandra Seed Oil Using CaO Derived from Snail Shell as Catalyst. Petroleum Science and Engineering. Vol. 2, No. 1, 2018, pp. 7-16. doi: 10.11648/j.pse.20180201.12

Received: March 20, 2018; Accepted: March 30, 2018; Published: May 7, 2018

\begin{abstract}
Due to the environmental problems caused by the use of fossil fuels, considerable attention has been given to biodiesel production as an alternative to petrol diesel. Biodiesel is ecofriendly, alternative diesel fuel prepared from domestic renewable sources that is, from vegetable oils and animal fats. It is a renewable source of energy which seems to be an ideal solution for global energy demand. In this study, the biodiesel production from kapok (Ceiba pentandra) seed oil with methanol has been considered in the presence of catalyst that is, $\mathrm{CaO}$ derived from snail shell. Optimum yield conditions were determined experimentally by changing certain parameters such as reaction time and temperature, at the end of the experiment, the maximum yield of $56.7 \%$ was obtained at $60^{\circ} \mathrm{C}$ and reaction time of 60 minutes. The physicochemical properties of the produced biodiesel were determined by ASTM procedures and were found to be comparable to ASTM standards for diesel fuel except for acid value which was above the recommended standard. Gas Chromatography-Mass Spectroscopy (GC-MS) demonstrated the presence of hydrocarbons.
\end{abstract}

Keywords: Biodiesel, Snail Shell, Transesterification, Renewable Energy

\section{Introduction}

The majority of energy consumed worldwide comes from fossil sources like petroleum, coal and natural gas [1]. However, these sources are limited and will be exhausted in the near future [1]. Depletion of the world's petroleum reserves, increase in environmental pollution and increase in demand of energy due to industrialization and pollution lead to search of alternative renewable source of fuels [2]. Developing countries such as Nigeria have a comparative advantage for bio-fuel production because of greater availability of land, favorable climatic conditions for agriculture and lower labor costs [2]. Diesel fuel is largely utilized in the transport, agriculture, commercial, domestic and industrial sectors for the generation of power/mechanical energy [1]. From the point of view of protecting the global environment and concern for long term supplies of conventional diesel fuels, it becomes necessary to develop alternative comparable with conventional fuels. Of the alternative fuels, vegetable oils are becoming a promising alternative to diesel fuels because they are renewable in nature and can be produced locally and eco-friendly as well [3]. The substitution of even small fraction of total consumption by alternative fuel will have a significant impact on the economy and the environment [1].

Biodiesel can be produced from both edible and non-edible oil as well as animal fats. Vegetable oils yielding trees absorbs more carbon dioxide from the atmosphere during their photosynthesis than they add to the atmosphere on burning. Hence, they essentially help to alleviate the increasing carbon dioxide content in the atmosphere. They have practically no sulfur content, offer no storage difficulty and they have excellent lubricating properties [4]. Several researchers have made systematic effort in the recent years to use the various vegetable oils as fuel in compression ignition engines. The viscosity of vegetable oil is about 11-17 times higher than that of diesel [1]. However, their use in direct injection diesel engines is restricted by some unfavorable physical properties, particularly their viscosity. The use of vegetable oil causes poor fuel atomization, incomplete combustion and carbon deposition on the injector and vale seats resulting in serious engine fouling. The commonly employed methods to reduce the viscosity of vegetable oils 
are (cited in [4])

a. Blending with diesel

b. Micro emulsion

c. Pyrolysis

d. Transesterification

Among the several methods for reducing the viscosity, transesterification is an extensive, commercial and most promising method of converting vegetable oils into diesel and also the by-product (glycerol) has commercial value [5].

Transesterification is the reaction of plants oils (triglycerides) with alcohol using alkaline catalyst to produce biodiesel and glycerol [6]. In the transesterification process, homogeneous alkaline catalyst that are commonly used are $\mathrm{NaOH}$ and $\mathrm{KOH}[6]$. One of the disadvantages in the use of a homogeneous catalyst in the process of biodiesel production is that the catalyst cannot be re-used or cannot be regenerated, because the catalyst is mixed with oil and methanol and also the process of separating the catalyst from the product is more complex. The use of this homogeneous catalysts is also not environmentally friendly because it requires a lot of water for the separation process, because of that, it is developed using solid catalysts in biodiesel production, such as Calcium oxide $(\mathrm{CaO})$ to overcome the lack of homogeneous catalyst [6]. Generally, Calcium oxide has a tolerance of moisture and free fatty acids and noncorrosive. Recently, Calcium oxide derived from natural resources such as chicken egg shell [7], Fish bone waste [8], Mollusk shell [9], Oyster shell [10] and Mussel shell [11] has been used as a heterogenous catalyst for biodiesel production.

At present, Ceiba pentandra seed oil does not find any major applications and hence even the natural production of seeds itself remain unidentified. In this study, typical nonedible high free fatty acid (FFA) content, Ceiba pentandra seed oil is considered as a potential feed stock for biodiesel production.

\section{Methods}

\subsection{Sample Collection and Treatment}

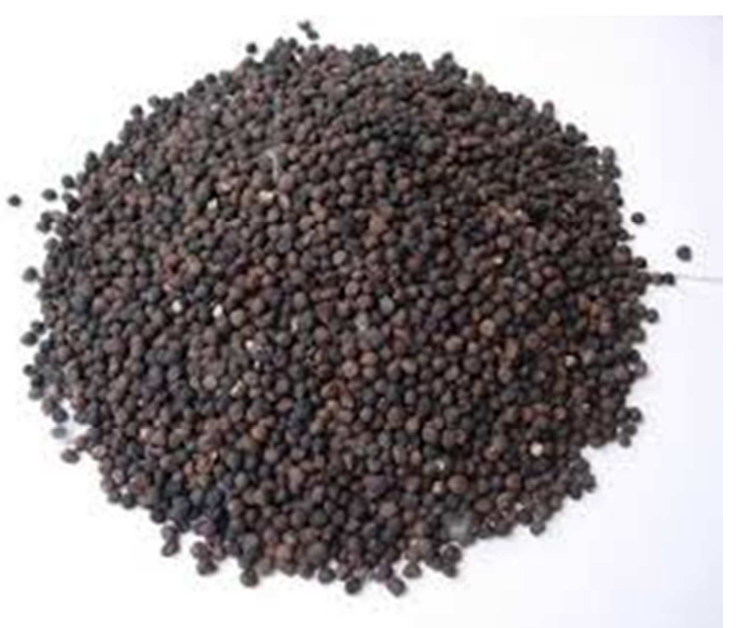

Figure 1. Ceiba pentandra seeds
The Ceiba pentandra (kapok) seeds were procured already matured and dried from Shinaka village of Goronyo Local Government Area of Sokoto State, Nigeria. The plant was identified as Ceiba pentandra by Herbarium Officer AbdulAzeez Salihu of the department of Biological Sciences, Botany Unit, Usmanu Danfodiyo University Sokoto. The gourds were opened, the seeds were shaken out and collected in a bowl. Defective seeds were selected and removed. It was sun dried and further grinded into powder using a clean mortar and pestle to ease extraction of oil.

\subsection{Catalyst Preparation}

$\mathrm{CaO}$ catalyst was prepared from snail shell by calcination method. The snail shell was cleaned thoroughly with running water for removal of organic matter and dried for whole night at $120^{\circ} \mathrm{C}$ and then the snail shell $(100-200$ mesh) was calcined at $850^{\circ} \mathrm{C}$ in air atmosphere with a heating rate of $10^{\circ} \mathrm{C} / \mathrm{min}$ for 4 hours. All calcined samples were kept in close vessel to avoid the reaction with humidity in air and carbon dioxide before use. Because the $\mathrm{CaO}$ catalyst will be reacted with $\mathrm{CO}_{2}$ and be converted into $\mathrm{CaCO}_{3}$, thus reducing its activity as a catalyst [12].

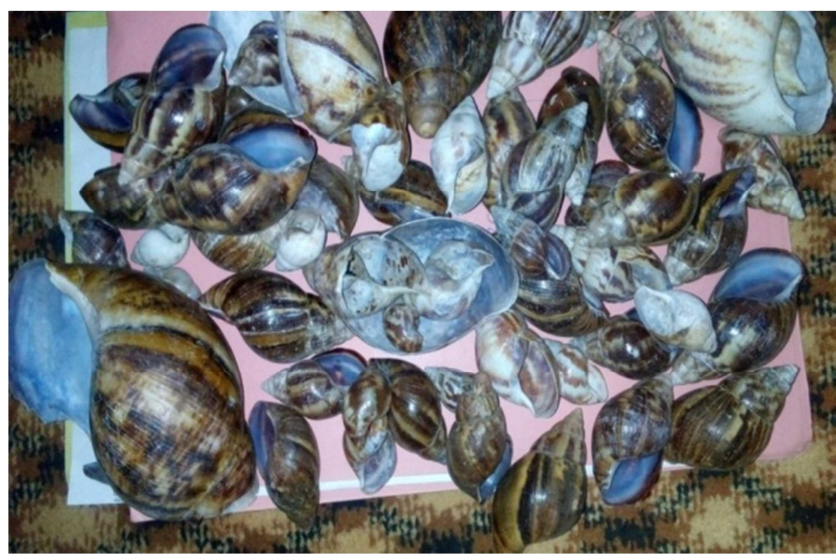

Figure 2. Snail Shells.

\subsection{Characterization of Catalyst}

FT-IR and Thermal Gravimetric Analysis (TGA) were conducted to characterize the catalyst.

\subsubsection{Thermal Gravimetric Analysis (TGA)}

Thermal gravimetric analysis (TGA) was carried out at Sokoto Energy Research Center, Usmanu Danfodiyo University Sokoto using TA-60WS thermal analyzer at a heating rate of $50^{\circ} \mathrm{C}$ per minute starting from room temperature up to $800^{\circ} \mathrm{C}$ in air atmosphere.

\subsubsection{FT-IR}

The FT-IR was also carried out at Sokoto Energy Research Center Usmanu Danfodiyo University Sokoto, using MB3000 model spectrophotometer. The transmission rate was set at the range of $4000-500 \mathrm{~cm}^{-1}$ and $950-400 \mathrm{~cm}^{-1}$ for Calcium carbonate and $\mathrm{CaO}$ respectively. The sample was mixed with alkali halide potassium bromide $(\mathrm{KBr})$ and compressed into a thin transparent pellet using hydraulic 
press and placed in standard sample compartment of the spectrometer and spectral data was obtained.

\subsection{Oil Extraction Using Soxhlet Extractor}

A medium size soxhlet apparatus was properly set up with the powdered sample $(120 \mathrm{~g})$ in a thimble and n-hexane solvent $\left(250 \mathrm{~cm}^{3}\right)$ in a round bottom flask. The solvent was boiled gently with the aid of a heating mantle. The vapor passing through the vapor tube was condensed by the condenser and the condensed hot solvent falls into the thimble containing the sample. The hot solvent slowly fills the body of the soxhlet, when it reaches the top of the siphon tube, it siphoned over into the flask. As the process continues, some portion of the substance was extracted. The process was repeated automatically until complete extraction was effected. The extract was heated to evaporate the remaining solvent and pure oil was obtained [3]. The percentage yield was calculated using the equation (1) [13].

$$
\% \text { Yield }=\frac{\text { Weight of extracted oil }}{\text { Weight of sample }} \times 100 \%
$$

\subsection{Physicochemical Analysis of Kapok Seed Oil}

\subsubsection{Determination of Acid Value and Free Fatty Acid}

The acid value measurement was carried out according to ASTM-D664 method. A solvent $\left(125 \mathrm{~cm}^{3}\right)$ consisting of $50 \%$ isopropyl alcohol and $50 \%$ toluene was properly prepared in a beaker $\left(600 \mathrm{~cm}^{3}\right)$. The sample $(2 \mathrm{~g})$ was added to the beaker followed by 2 drops of phenolphthalein indicator. The solution was titrated with $\mathrm{KOH}(0.1 \mathrm{M})$ until the color changed to pink. The acid value was calculated using equation (2)

$$
\mathrm{AV}=\frac{56.1 \times \mathrm{M}}{\mathrm{W}} \times \text { Titre value }
$$

Where $\mathrm{AV}=$ Acid value

$\mathrm{M}=$ Molarity of $\mathrm{KOH}$

$56.1=$ Molecular weight of $\mathrm{KOH}$

$\mathrm{W}=$ Weight of the sample

While Free Fatty Acid (FFA) was calculated using equation (3) [14]

$$
\mathrm{FFA}=0.5 \times \mathrm{AV}
$$

\subsubsection{Determination of Saponification Value}

The oil sample $(2.0 \mathrm{~g})$ was weighed into a distillation flask and Ethanolic potassium hydroxide $\left(20 \mathrm{~cm}^{3}, 0.5 \mathrm{M}\right)$ was added. The flask was heated under reflux for 30 minutes and was then allowed to cool to room temperature. The excess potassium hydroxide was then back titrated with hydrochloric acid $(0.5 \mathrm{M})$ using phenolphthalein indicator. A blank titration was conducted under the same condition without the oil [15]. Saponification value was calculated using equation (4) [16].

$$
\text { Saponification value }=\frac{56.1 \times N\left(V_{0}-V_{1}\right)}{W}
$$

Where $\mathrm{V}_{0}=$ Volume of hydrochloric acid used in the blank titration
$\mathrm{V}_{1}=$ Volume of hydrochloric acid in the test sample titration

$\mathrm{N}=$ Actual normality of the $\mathrm{HCl}$ used

$\mathrm{W}=$ Weight of oil

\subsubsection{Determination of Iodine Value}

The sample $(2.0 \mathrm{~g})$ was weighed into a conical flask, carbon tetrachloride $\left(20 \mathrm{~cm}^{3}\right)$ was added to dissolve the oil, Dam's reagent $\left(25 \mathrm{~cm}^{3}\right)$ was added to the mixture. The content was vigorously swirled and then kept in the dark for $1 \frac{1}{2}$ hour. $10 \%$ potassium iodide $\left(20 \mathrm{~cm}^{3}\right)$ and water $(100$ $\mathrm{cm}^{3}$ ) were added into the content using measuring cylinder. The content was titrated against sodium thiosulphate solution $(0.1 \mathrm{M})$ with vigorous shaking until the yellow color disappeared, then $1 \%$ starch indicator $\left(1 \mathrm{~cm}^{3}\right)$ was added and titration continues to the colorless end point. A blank titration without the sample was conducted using the same procedure. The iodine value was calculated using equation (5) [17-18].

$$
\text { Iodine value }=\frac{126.9 \times \mathrm{M} \times(\mathrm{V} 1-\mathrm{V} 2)}{\mathrm{W}}
$$

Where $\mathrm{M}=$ Molarity of sodium thiosulphate

$\mathrm{V}_{1}=$ Volume of sodium thiosulphate in blank titration

$\mathrm{V}_{2}=$ Volume of sodium thiosulphate in the oil sample titration

$\mathrm{W}=$ Weight of the sample

\subsection{Experimental Design}

Response Surface (Box-Bechnken) statistical experimental design was used to design the optimization. Four independent variables namely; reaction time, temperature, amount of methanol to oil ratio and catalyst concentration were selected for investigation. Methanol to oil ratio and catalyst concentration were kept constant while reaction time and temperature were varied.

Table 1. shows the lower and upper factors employed. Each run was completely randomized to obtain a total of four runs. The experiment was designed using MINITAB 17 Statistical Software.

Table 1. The Process Variables and their Levels.

\begin{tabular}{lll}
\hline Factor & Lower level & Upper level \\
\hline Temperature $\left({ }^{\circ} \mathrm{C}\right)$ & 60 & 65 \\
Time $(\min )$ & 60 & 120 \\
\hline
\end{tabular}

\subsection{Transesterification Using $\mathrm{CaO}$}

Each run involves kapok seed oil $\left(10 \mathrm{~cm}^{3}\right)$ in a beaker, the amount of methanol and catalyst were added, the mixture was refluxed in water bath for a period of time at a particular temperature as specified in the design matrix. At the end of the reaction time, the spent catalyst was recovered from the bottom layer by centrifuging at (200 rpm, 1 hour), the mixture was transferred into a separating funnel, distilled water $\left(10 \mathrm{~cm}^{3}\right)$ and $\mathrm{n}$-hexane $\left(10 \mathrm{~cm}^{3}\right)$ was added to facilitate the separation into aqueous phase and organic phase. The aqueous glycerol was discarded and biodiesel was recovered. The percentage biodiesel yield was calculated using equation (6) [19]. 


$$
\begin{array}{r}
\% \text { Biodiesel Yield }= \\
\text { Weight of biodiesel } \div \text { Weight of oil } \times 100 \%(6)
\end{array}
$$

\subsection{Fuel Properties of the Biodiesel Produced}

Some of the properties of fuel which are used for assessing the nature and quality diesel fuel include acid value, specific gravity or density, flash point, pour point, viscosity, high heating value and cetane number.

\subsubsection{Determination of Specific Gravity}

Specific gravity is the ratio of the density of a fuel to the density of a reference substance or ratio of mass of a fuel to the mass of a reference substance. Specific gravity was determined according to ASTMD-1298 method. A dry empty beaker was weighed and the mass was recorded as $\mathrm{W}_{\mathrm{o}}$, a certain amount of water was added and weighed again, the mass was recorded as $\mathrm{W}_{1}$, equal amount of the sample as the water was equally weighed in a beaker, the mass was recorded as $\mathrm{W}_{2}$. The specific gravity of the sample was calculated using equation (7) $[15,18]$.

$$
\text { Specific Gravity }=\frac{W_{2}-W_{0}}{W_{1}-W_{0}}
$$

\subsubsection{Determination of Cetane Number}

Cetane number $(\mathrm{CN})$ of the sample was calculated from saponification and iodine values using equation (8) [20]

$$
\text { Cetane number }=46.3+\frac{5458}{S V}-0.225(\mathrm{IV})
$$

\subsubsection{High Heating Value (HHV)}

High heating value of the sample was estimated from saponification number and iodine value using equation (9) $[21,22]$.

$$
\mathrm{HHV}=49.43-0.041 \mathrm{SV}-0.015 \mathrm{IV}
$$

\subsubsection{Kinematic Viscosity}

Kinematic viscosity is the resistance to flow of fluid under gravity. The kinematic viscosity is equal to the dynamic viscosity divide by density. The kinematic viscosity is a basic design specification for the the fuel injectors used in diesel engines. Too high a viscosity and the injectors do not perform properly [23].

\subsubsection{Flashpoint}

According to ASTM definition, flashpoint is a measure of the temperature to which a fuel must be heated such that a mixture of the vapor and air above the fuel can be ignited. The flashpoint was determined according to ASTM D93 method. The sample was placed in the test cup to the prescribed mark in the interior of the cup. The cup was mounted onto its position on the tester. Bunsen burner was used to supply heat to the apparatus at the rate of $1^{\circ} \mathrm{C}$ per minute with constant stirring. A small test flame was directed into the cup intermittently. The flashpoint was taken as the temperature when the flame caused the vapor above the sample to ignite [24].

\subsubsection{Determination of Pour Point}

Pour point is the lowest temperature at which a liquid will cease to flow. The pour point was determined according to ASTM D97 method. The sample was poured into the test jar to the mark. A thermometer was then immersed $3 \mathrm{~mm}$ below the sample surface and the jar was placed on the disk inside the bath jacket maintained at $6^{\circ} \mathrm{C}$. At every $3^{\circ} \mathrm{C}$ decrease in temperature, the jar was removed from the jacket and was tilted to ascertain flow of the sample. This was repeated until the sample cease to flow when tilted for a period of 3 seconds. The temperature at this point was recorded. The pour point was calculated by adding $3^{\circ} \mathrm{C}$ to the recorded temperature [25].

\subsubsection{Sulphur Content}

The sulphur analyzer was turned on using a key and allowed to warm up for three minutes at a wavelength of $0.537 \mathrm{~nm}$. The sample was poured into a sample container consistent with the instrument being used and filled above a minimum depth. A window cell sealed with transparent polyethene was then used to cover the sample and a cap was used to close it tight. It was placed onto the sample holder of the analyzer. The button bearing measure was pressed and triplicate readings, after ten seconds each were displayed by the machine. The readings were recorded and the mean of the values represent the sulphur content in the sample [26].

\subsubsection{Fatty Acid Methyl Ester Analysis}

The Fatty Acid Methyl Ester was performed using GCMS-Q2010 PLUS. $2 \mu \mathrm{L}$ of biodiesel sample was injected into the Elite column-5MS. The injection was performed in split mode (10:1). The oven temperature was initially held at $70^{\circ} \mathrm{C}$ for $5 \mathrm{~min}$, later increased to $240^{\circ} \mathrm{C}$ at $10^{\circ} \mathrm{C} / \mathrm{min}$, and then held for 5 minutes. The injector, transfer and source temperature were set at $250^{\circ} \mathrm{C}, 200^{\circ} \mathrm{C}$ and $150^{\circ} \mathrm{C}$ respectively. The carrier gas was helium and the total scan time was 24 minutes.

\subsection{Data Analysis and Presentation}

The experimental results were analyzed using MINITAB 17 statistical Analysis software. The results of statistical analysis were presented using Main Effect Plot, Interval plot and Contour Plot.

\section{Results}

\subsection{Percentage Yield}

The percentage yield of kapok oil extracted was $21.8 \%$. The result indicate that kapok seed is a good source of oil which could be used for biodiesel production. The yield obtained is slightly lower than that reported by (cited in [1]). 
Table 2. Physicochemical Properties of Kapok Oil.

\begin{tabular}{ll}
\hline Properties & Kapok seed oil \\
\hline Saponification value & $129.03 \pm 0.07$ \\
Iodine value $\left(\mathrm{gI}_{2} / 100 \mathrm{~g}\right)$ & $94.54 \pm 0.1$ \\
Acid value $(\mathrm{mgKOH} / \mathrm{g})$ & $15.99 \pm 0.16$ \\
Free fatty acid $(\%)$ & 7.99 \\
Density $\left(\mathrm{g} / \mathrm{cm}^{3}\right)$ & 0.892 \\
Viscosity & 47.0 \\
Cloud point & 28.10 \\
Pour point & 16.60 \\
\hline
\end{tabular}

Table 3. Design Matrix and Experimental Results.

\begin{tabular}{lllllllll}
\hline Std Order & Run Order & Center Pt & Blocks & Cat. Conc. & MeOH/oil & Temp $\left({ }^{\circ} \mathbf{C}\right)$ & Time $(\mathbf{m i n})$ & \%Yield \\
\hline 1 & 4 & 1 & 1 & 0.1 & $9: 1$ & 65 & 60 & 50.7 \\
2 & 3 & 1 & 1 & 0.1 & $9: 1$ & 65 & 120 & 36.2 \\
3 & 2 & 1 & 1 & 0.1 & $9: 1$ & 60 & 60 & 56.7 \\
4 & 1 & 1 & 1 & 0.1 & $9: 1$ & 60 & 120 & 53.1 \\
\hline
\end{tabular}

Table 4. Physicochemical Properties of Biodiesel from Ceiba pentandra Oil.

\begin{tabular}{lll}
\hline Parameter & Kapok Oil Biodiesel & Biodiesel ASTM Standard \\
\hline Sulphur content $(\%)$ & $0.0205 \pm 0.005$ & 0.005 \\
Kinematic viscosity $\left(\mathrm{mm}^{2} / \mathrm{s}\right)$ & 18.47 & $1.9-+6.0$ \\
Cetane number & 83.28 & $47 \mathrm{~min}$ \\
High heating value $(\mathrm{mJ} / \mathrm{kg})$ & 43.98 & $---130 \mathrm{~min}$ \\
Flash point $\left({ }^{\circ} \mathrm{C}\right)$ & 138 & $-15-16$ \\
Pour point $\left({ }^{\circ} \mathrm{C}\right)$ & 9.3 & $0.9 \mathrm{max}$ \\
Specific gravity & 0.979 & $0.9 \mathrm{max}$ \\
Density $\left(\mathrm{g} / \mathrm{cm}^{3}\right)$ & 0.839 & \\
\hline
\end{tabular}

Table 5. Fatty Acid Methyl Ester (FAME) of the Biodiesel produced from kapok seed oil.

\begin{tabular}{lll}
\hline Saturated FAME & Quality & Area percent \\
\hline Hexadecanoic acid, methyl ester & 95 & 49.70 \\
15-Tetracosenic acid, methyl ester, (Z)- & 53 & 7.67 \\
9,17- Octadecadienal, (Z)- & 95 & 0.88 \\
Total & & 58.25 \\
Unsaturated FAME & & 0.77 \\
(S)-(+)-5-Methyl-1-heptanol & 53 & 2.33 \\
Cis-3-Methylpent-3-ene & 83 & 2.52 \\
3-Hexene,2,2,5,5-tetramethyl-, (Z)- & 50 & 2.44 \\
2,4-Decadienal, (E, E)- & 90 & 0.98 \\
2-Propene-1-amine, N-ethyl-N-methyl & 35 & 4.02 \\
2-Tridecenal,(E)- & 47 & 7.67 \\
9-Octadecenoic acid(Z)-2,3-dihydropropyl ester & 58 & 1.24 \\
2-Octenal, (E)- & 83 & 9.56 \\
9-Oxabicyclo (6.1.0) nonane, cis- & 83 & 31.53 \\
Total & & 0.52 \\
Non-FAME & & 1.55 \\
Heptanal & 64 & 0.55 \\
Octanal & 64 & 4.02 \\
3- Octan-2-one & 62 & 1.39 \\
2-Undecenal & 52 & 6.72 \\
Oleic acid & 98 & 14.75 \\
12-Hydroxydodecanoic acid & 38 & \\
Total & & \\
\hline
\end{tabular}




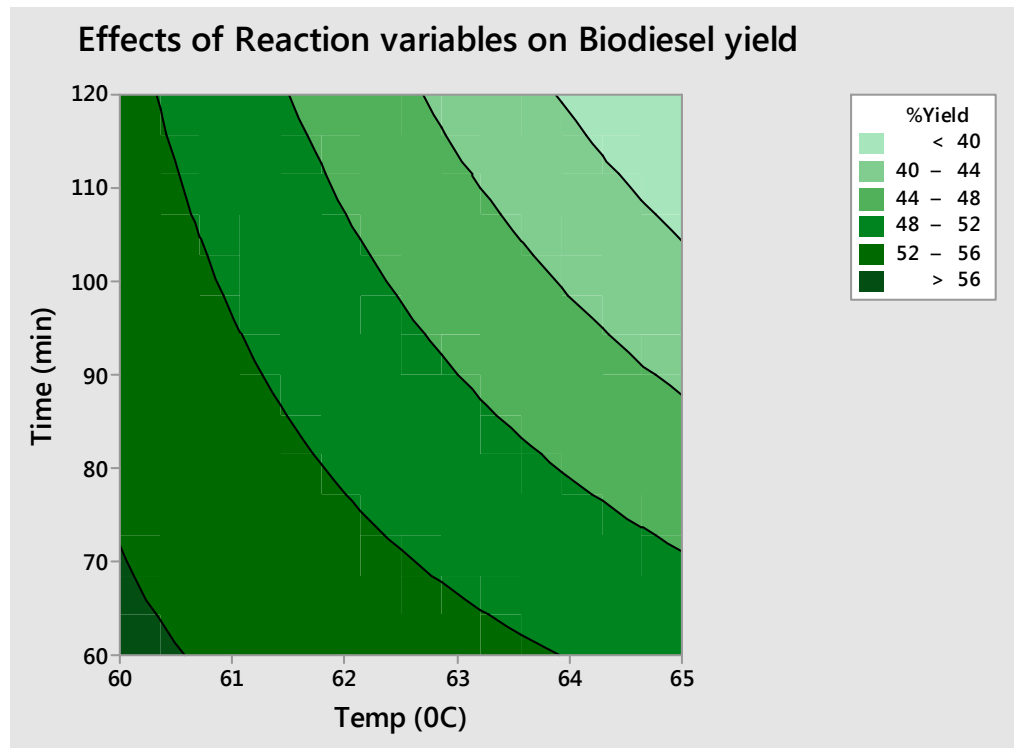

Figure 3. Contour plot showing the combined effect of reaction variables (time and temperature) on biodiesel yield with the amount of methanol and catalyst concentration held constant.

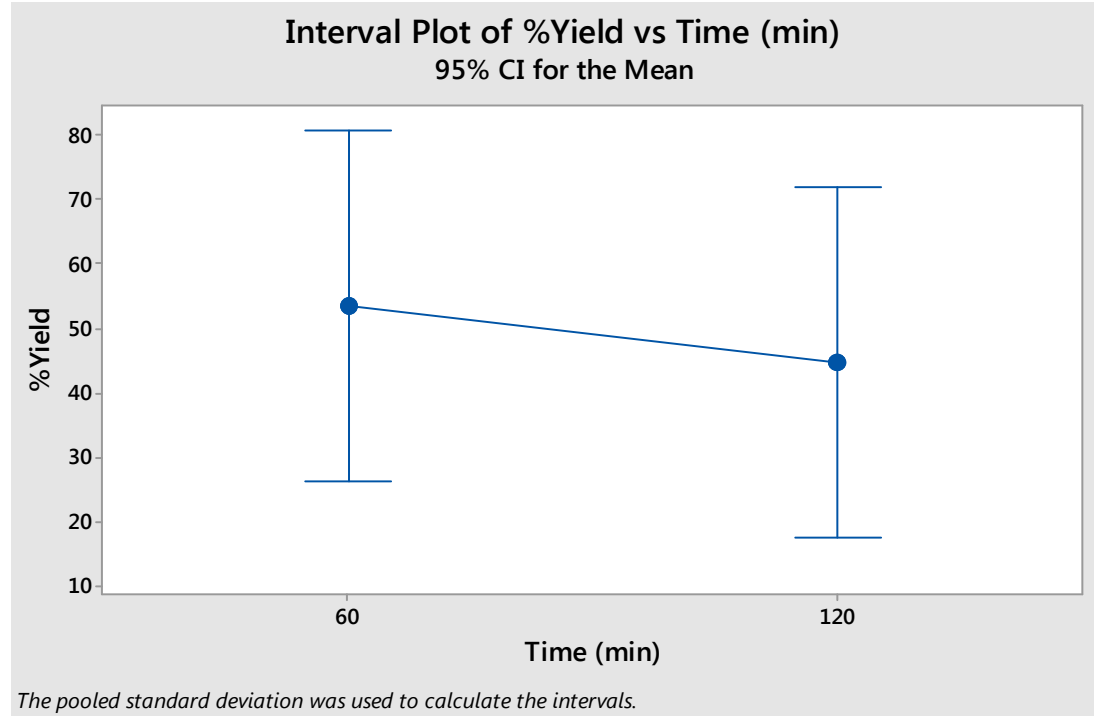

Figure 4. Interval Plot of\% Yield versus Time (min).

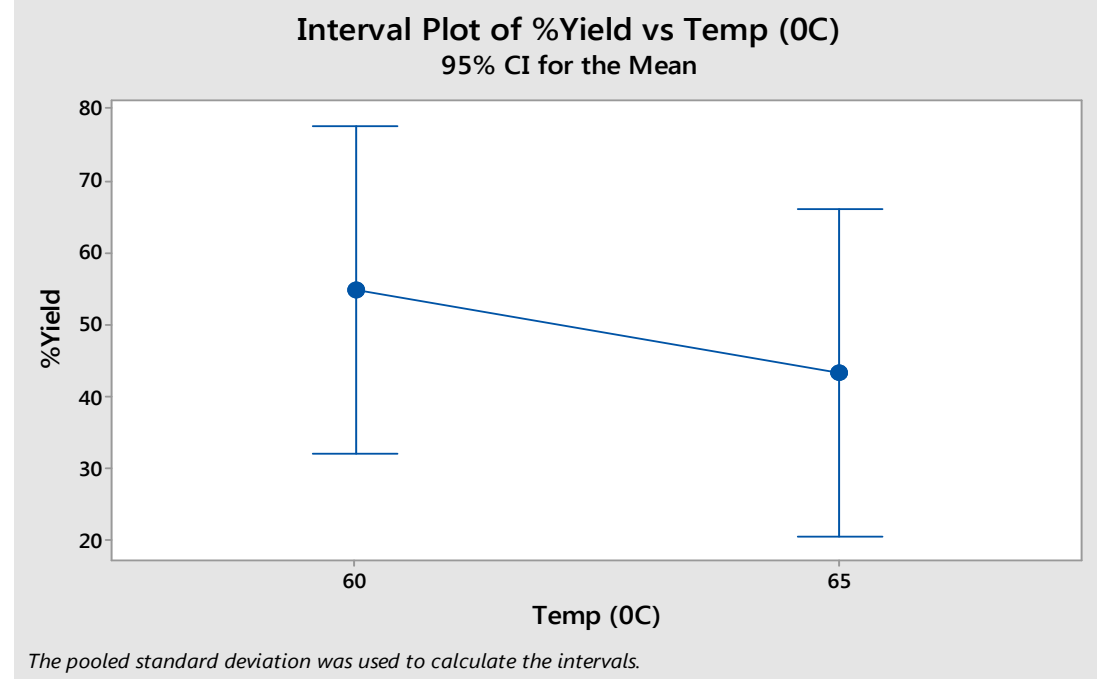

Figure 5. Interval Plot of \% Yield versus Temperature. 
perator: USER

epartment: BIOMASS

TLE: MS_GSS

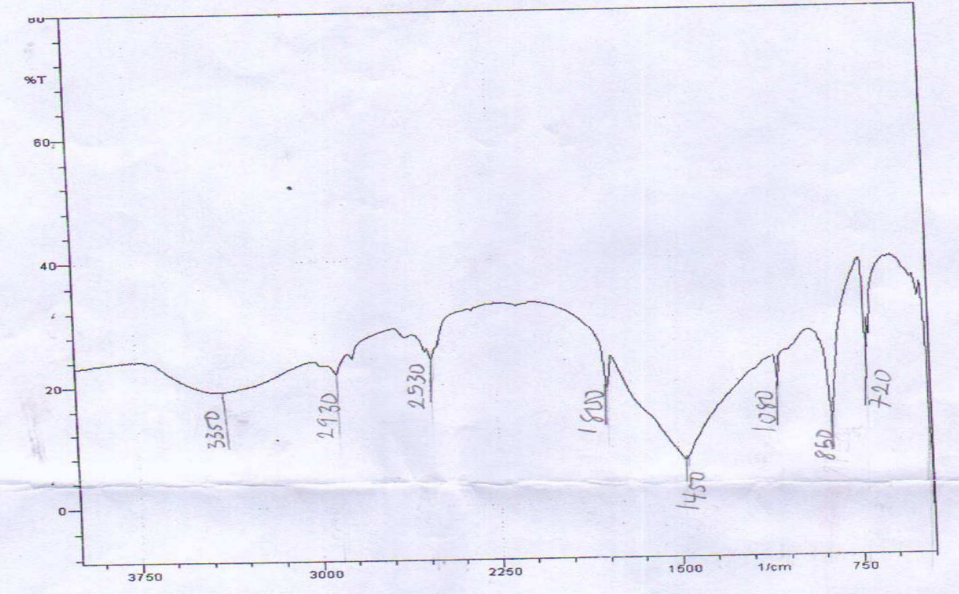

Figure 6. FT-IR of the Catalyst derived from Snail Shell (CaO) before Calcination.

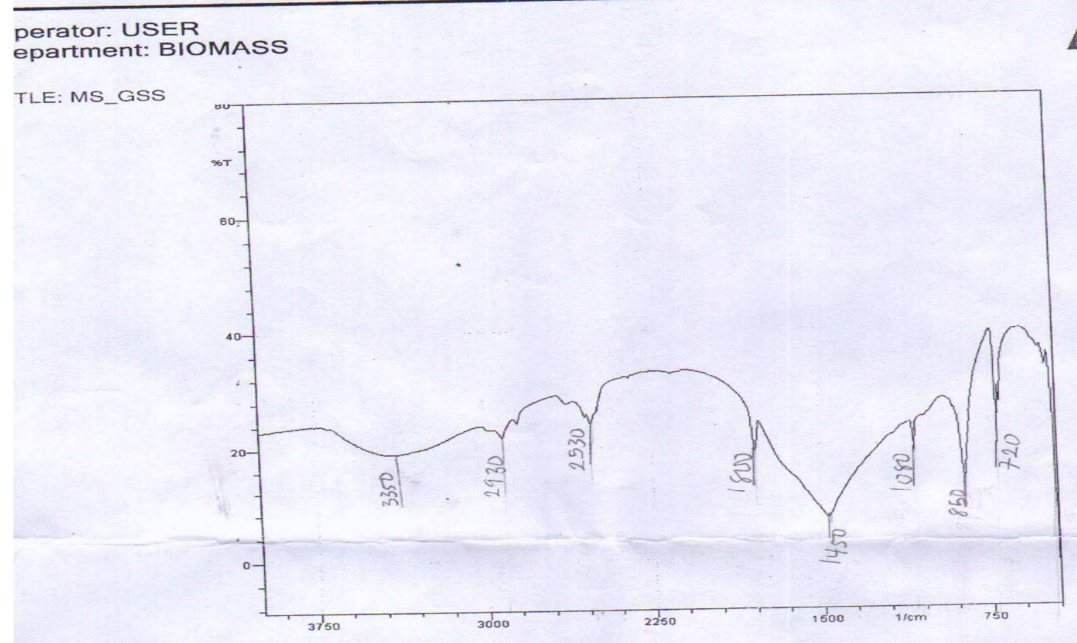

Figure 7. FT-IR of the Calcined Catalyst.

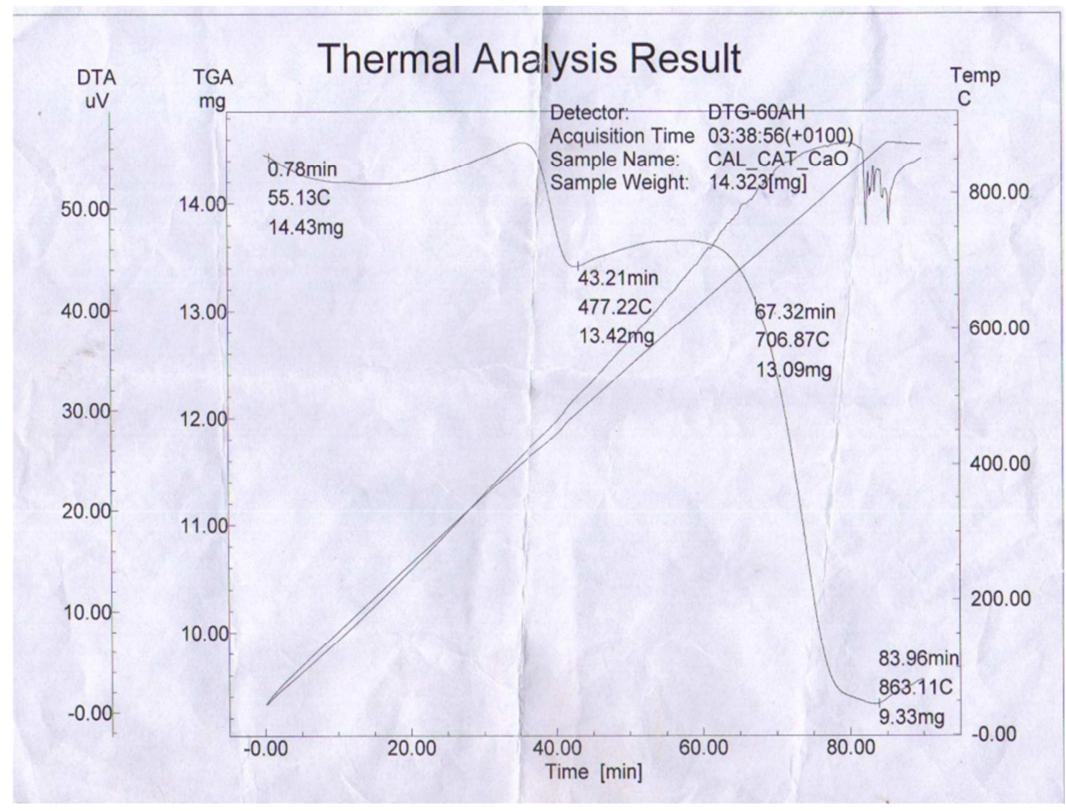

Figure 8. Thermal Gravimetric Analysis of the Catalyst. 


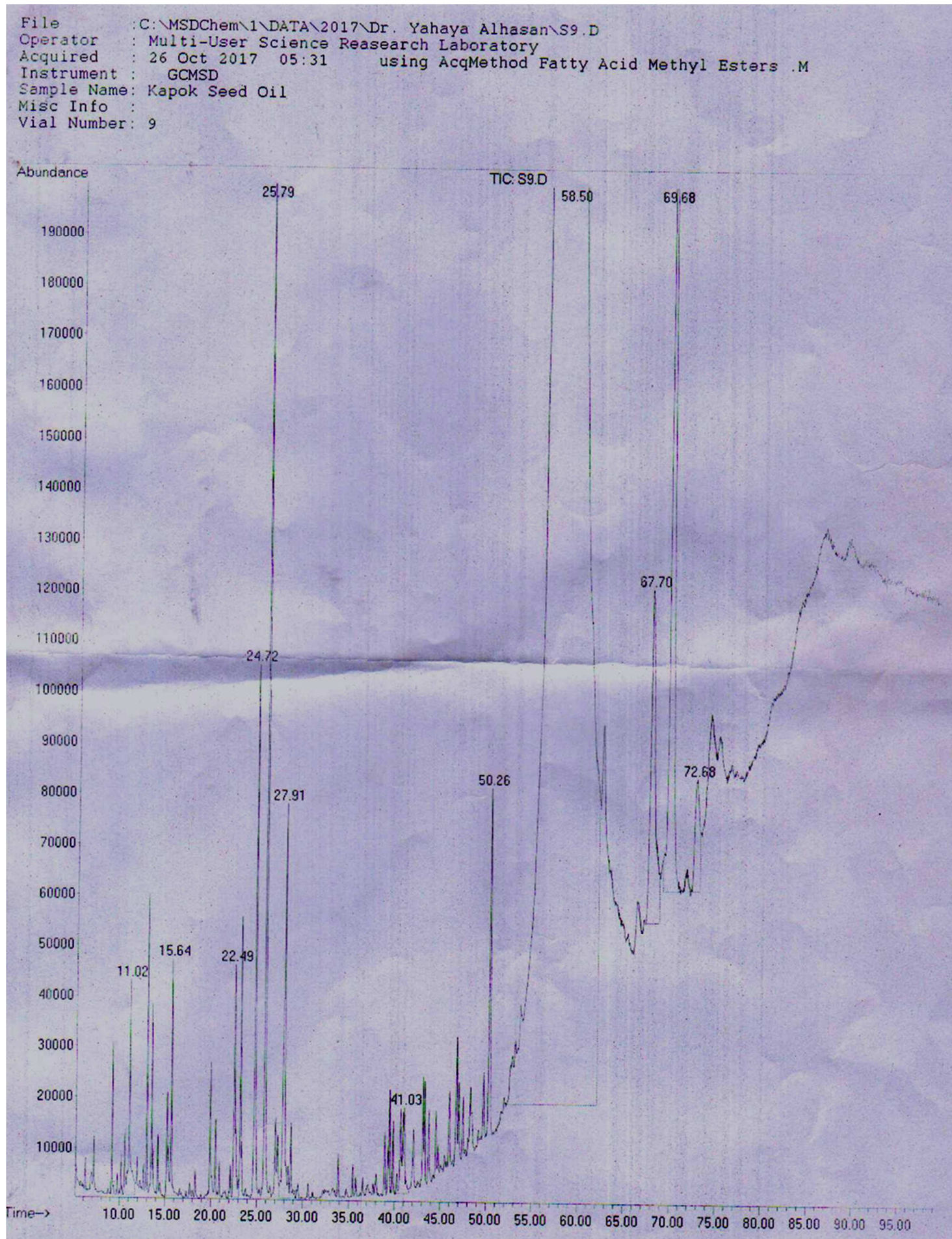

Figure 9. GC-MS spectra of the Biodiesel produced.

\section{Discussion}

Acid value is the measure in milligram of potassium hydroxide per gram required to titrate a sample to a specified end point. It is a direct measure of FFA present in the oil. Excess or higher acid and free fatty acid values of oil greater than $5 \%$ is not suitable for base catalyzed transesterification reaction. The acid value $15.99 \pm 0.16$ as shown in Table 2 above, is high but lower than $32.54 \mathrm{mgKOH} / \mathrm{g}$ obtained by.
Iodine value is the measure of average amount of unsaturation of fats and oils which indicate the suitability of oil for production of biodiesel. The value obtained for Kapok seed oil is $94.54 \pm 1.60 \mathrm{gI}_{2} / 100 \mathrm{~g}$ as seen in Table 2 above, is within the range reported by (cited in [27]) for kapok seed oil.

Saponification value obtained is slightly lower than 163 $\mathrm{mgKOH} / \mathrm{g}$ [28]. Higher saponification value indicates the oil is normal triglycerides and is useful in production of liquid 
soap in shampoo industries. The saponification value of is $129.03 \pm 0.07 \mathrm{mgKOH} / \mathrm{g}$ which is higher than that reported by (cited in [20]) for gingerbread plum.

The Kinematic viscosity of the biodiesel produced is 18.47 $\mathrm{mm}^{2} / \mathrm{s}$, the kinematic viscosity is the measure of the resistance to flow of a liquid under gravity.

The Cetane Number of he Biodiesel produced is 83.28 minutes, Cetane number $(\mathrm{CN})$ is a measure of the ignition performance of a fuel [23]. It is fuel quality parameter that is related to the ignition delay time and combustion quality of a fuel, it measures the readiness of a diesel fuel to auto ignite when injected into the diesel engine [29]. A fuel with high cetane number indicates good ignition quality, the higher the cetane number the shorter the ignition delay and the higher the propensity of the fuel to ignite [30].

Gas Chromatography-Mass Spectrometry (GC-MS) was used to determine the chemical compositions of the biodiesel produced. In this analysis, different esters and non-ester compounds were detected at different retention times. The percentage peak area and names of the different compounds identified in the biodiesel sample is shown in table 5 above.

Figure 7 above shows the infrared spectrum of calcium carbonate $\left(\mathrm{CaCO}_{3}\right)$ and synthesized calcium oxide $(\mathrm{CaO})$ from snail shell. A sharp peak can be seen at $1450 \mathrm{~cm}^{-1}$ of snail shell calcium carbonate. The absorption peaks correspond to C-O symmetrical stretching vibration of carbonates. The absorption peak at $1800 \mathrm{~cm}^{-1}$ and $2530 \mathrm{~cm}^{-1}$ correspond to $\mathrm{C}=\mathrm{O}$ stretching vibration of carbonates [31]. The two weak peaks at $1080 \mathrm{~cm}^{-1}$ and $850 \mathrm{~cm}^{-1}$ correspond to the out of plane bending vibration of $\mathrm{C}-\mathrm{O}$ bonds of carbonates.

Upon calcinations, the calcium carbonate was thermally decomposed into calcium oxide and loses carbonate. Thus, this leads to decrease of characteristics peak of carbonate on the IR spectrum of the synthesized calcium oxide. The reduced intensity of absorption band which correspond to carbonate can be seen at $2470 \mathrm{~cm}^{-1}, 1650 \mathrm{~cm}^{-1}, 1450 \mathrm{~cm}^{-1}$, $900 \mathrm{~cm}^{-1}$ and $750 \mathrm{~cm}^{-1}$ on the IR spectrum of calcium oxide from snail shell [32].

A sharp peak around $480 \mathrm{~cm}^{-1}$ of the infrared spectrum corresponds to functional group $\mathrm{Ca}-\mathrm{O}$ peak intensity reduced as calcium carbonate was decomposed to calcium oxide. The absorption band in the range $3450-3920 \mathrm{~cm}^{-1}$ on the infrared spectrum corresponds to hydroxyl group. The absorption peak of hydroxyl group is normally ascribed to the presence of calcium hydroxide. The existence of hydroxyl group resulted from absorption of atmospheric moisture during FTIR analysis which subsequently formed calcium hydroxide. This phenomenon is common due to the high hydrophilicity nature of the compound [33].

The Thermal Gravimetric Analysis (TGA) shows that $14.323 \mathrm{mg}$ of the $\mathrm{CaO}$ derived from snail shell was inserted into the TGA machine, at 43.21 minutes and the temperature of $477.22^{\circ} \mathrm{C}$, the weight of the catalyst reduced to $13.42 \mathrm{mg}$. This may be due to loss of moisture and other impurities absorbed by the catalyst. At $67.32 \mathrm{~min}$, the weight of the catalyst was $13.09 \mathrm{mg}$. As the temperature continues to rise to $863.11^{\circ} \mathrm{C}$ and 83.96 minutes, the weight was significantly reduced to $9.33 \mathrm{mg}$. Reduction the weight might be due to loss of $\mathrm{CO}_{2}$ and other uncalcined carbonates that are within the catalyst.

\section{Conclusion}

The study was focused on the production of biodiesel from Ceiba pentandra seed oil using $\mathrm{CaO}$ derived from snail shell as a catalyst as well as optimization of the production, characterization of the catalyst and characterization of the produced biodiesel using GC-MS. Beside the physicochemical properties of the crude oil and the produced biodiesel were determined, this study has also demonstrated the feasibility of using calcium oxide derived from snail shell as catalyst to produce biodiesel from kapok seed oil. The response surface technique was used to determine the optimal condition that can be used to produce biodiesel from kapok (Ceiba pentandra) seed oil. The optimal process parameter for biodiesel production are reaction time of 60 minutes, reaction temperature of $60^{\circ} \mathrm{C}$, catalyst concentration of $1(\%$ wt of oil) and methanol to oil ratio of 9:1 respectively. The optimum yield of biodiesel was found to be $56.7 \%$. The result shows that kapok seed oil can be used as an alternative to petrol diesel.

\section{Recommendations}

Based on the findings in this research the following recommendations were made:

1. Pretreatment of the crude kapok oil should be employed before carrying out the transesterification so as to reduce the acid content of the oil.

2. Evaluation of engine performance of the produced biodiesels.

3. Further studies on the efficient method of producing the biodiesel from kapok seed that could minimize the energy input and maximize the output.

\section{References}

[1] Kathirvelu S., Shenbaga V. M. N., Neela K., Mayilsamy K and Krishnaswamy. (2014). ARPN Journal of Engineering and Applied Science: www.arpnjournals.com

[2] Muktar, M., Muhammad, C., Dabai, M. U. and Mamuda, M. (2015). Ethanolysis of Calabash (Lageneria sinceraria) Seed Oil for The Production of Biodiesel. American Journal of Energy Engineering. 2(6): 141-145.

[3] Barnwal, B. K and Sharma, M. P. (2005). Prospect of Biodiesel Production from.

[4] Ramadhas A. S., Jayaraj S. and Muraleedharan C. (2004). Use of Vegetable Oil as I. C. Engine fuels- A Review. Renewable Energy. 29:727-742.

[5] Hanny J. B and Shizuko H. (2008). Biodiesel Production from Crude Jatropha Curcas L. Seed Oil with a High Content of Free Fatty Acids. Bioresource Technology. 99: 1716-1721. 
[6] Endah, M., Marhaeni, P., Rachimoellah, M., Nidya, S. and Ferdy, P. (2012). Global Journal of Researches in Engineering, Chemical Engineering. 12(2): Version 10.

[7] Chojnaka, K. (2005). "Bioabsorption of Cr(III) Ions by Egg Shells. Journal of Hazardous Material. 121:167-173.

[8] Sulaiman S., Syakirah, Khairudin N., Jamal P. and Alam M. Z. (2015). "Fish Bone Waste as Catalyst for Biodiesel Production". Journal of Tropical Resources and Sustainable Science. 3: 180-184.

[9] Viriya-Empikul N, Krasae P, Puttasawat B, Yoosuk B, Chollacoop N and Faungnawakij K. (2010). Waste Shell of Mollusk and Egg as Biodiesel Production Catalysts, Bioresour Technol: 101(10): 3765-7.

[10] Nakatani, N., Takamori, H., Takeda, K. and Sakugawa, H. (2009). "Transesterification of Soybean Oil Using Combusted Oyster Shell Waste as a Catalyst". Bioresource Technology. 100: 1510-1513.

[11] Rezaei, R., Mohadesi, M. M. and Moradi, G. R. (2013). "Optimization of Biodiesel Production Using Waste Mussle Shell Catalyst”. Fuel. 109: 534-541.

[12] Mohan S. K. (2015). Studies on Optimization of Biodiesel Production- Snail Shell as Eco-Friendly Catalyst by Transesterification of Neem Oil.

[13] Hossain, S. A., Salleh, B. M,. Boyce, A., Chowdhury, A. N. and Naqiuddin, M. (2008). Biodiesel Fuel Production from Algae as Renewable Energy. American Journal of Biochemistry and Biotechnology. 4(3):250-251.

[14] Gandure, J., Ketlogetwe, C. and Temu, A. (2013). Fuel Properties of Jatropha Methyl Ester and Its Blends with Petroleum Diesel. Journal of Engineering and Applied Science. 8(11): 900-903.

[15] Ved, K. and Padam, K. (2013). Study of Physicochemical Properties of Biodiesel from Sorghum Oil. Research Journal of Chemical Sciences. 3(9):64-67.

[16] Akpan U. G., Jimola A. and Mohammed A. D. (2006). Extraction, Characterization and $\mathrm{M}$, odification Of Castor Seed Oil. Leonardo Journal of Science. 8: 43-52.

[17] Birnin-Yauri, A. U. and Garba, S. (2011). Comparative Studies on Some Physicochemical Properties of Baoba, Vegetable, Peanut and Palm Oils. Nigerian Journal of Basic and Applied Science. 19(1): 64-67.

[18] Awab W. Al-Harbawy and Mozahim K. Al-Mallah (2014). Prtoduction and Characterization of Biodiesel from seed oil of Castor (Ricinus communis L.) plant, IJST 3(9) 508-513.

[19] Heroor, S. H. and Rahul, S. D. (2013). Production of Biofuel from Crude Neem Oil and It Performance. International Journal of Environment Engineering and Management. 4(5): 425-432.

[20] Salaheldeena, M., Aroua, M. K and Mariod, A. A. (2015). Physicochemical Characterization and Thermal Behavior of Biodiesel and Biodiesel-Diesel Blends Derived from Crude Moringa Peregrina seed Oil. Journal of Energy Conversion and Management. 92: 532-542.

[21] Demirbas, A. (2008). Biodiesel from Vegetable Oils Via Esterification in Supercritical Methanol. Energy Conversion
Management. 43(23):49-56.

[22] Sokoto, A. M., Hassan, L. G. and Dangoggo, S. M. (2011). Influence of Fatty Acid Methyl Ester On Fuel Properties Of Biodiesel Produced From Curcubitapopo. Nigerian Journal of Basic Applied Science. 19:81-86.

[23] Gerpen, J. V., Shanks, B., Pruszko, R., Clement, D. and Knothe, G. (2004). Biodiesel Production Technology. National Renewable Energy Laboratory, 1617 Cole Boulevard; Colorado. USA. Pp 22-28.

[24] Indhumathi, P., Shabudeen, P. S. and Shoba, U. S. (2014). A Method for Production and Characterization of Biodiesel from Green Micro Algae. International Journal of Bio-Science and Bio-Technology. 6(5): 111-122.

[25] Thirumarimurugan, M., Sivakumar, V. M., Xavier, A. M., Prabhakaran, D. and Kannadasan, T.(2012). Preparation Of Biodiesel From Sunflower Oil By Transesterification. International Journal of Bioscience and Bioinformations.2(6): 441-444.

[26] American Standard for Testing and Materials (ASTM). (1998). Standard Test Method for Sulphur in Petroleum and Petroleum Products By Energy Dispersive X-ray Flourescence Spectrometry, Annual Book of ASTM Standards. 5(3): 805808.

[27] Muhammad, C., Ladan, M. J. and Wasagu R. U. S. (2006). Comparative Analyses of Vegetable Oils Sold in Bodinga, Sokoto State, Nigeria. Biological and Environmental Science Journal for The Tropics. 3(1): 113-116.

[28] Muthu, H., Sathyaselvabala, V., Varathachary, T., KiruphaSelvaraj, D., Nandagopal, J., and Subramanian, S. (2010). Synthesis of Biodiesel from Neem Oil by Two-Step Tranesterification. Braziliian Journal of Chemical Engineering. 27(4): 601- 608.

[29] Fakhary, E. M. And El-Maghraby, D. M. (2013). Fatty Acids Composition and Biodiesel Characterization of Dunaliella Salina. Journal of Water Resource and Protection. 5: 894899.

[30] Mukhtar, M. and Dabai, M. U. (2016). Production and Fuel Properties of Biodiesel from Gingerbread Plum (Parinari Macrophylla) Seed Oil Using $\mathrm{MgO} / \mathrm{Al}_{2} \mathrm{O}_{3}$ Catalyst. American Journal of Environmental Protection. 5(5): 128-133.

[31] Garcia J., Lopez T., Alvarez M., Aguilar D. H. and Quintana P. (2008). "Spectroscopic, Structural and Textural Properties of $\mathrm{CaO}-\mathrm{SiO}_{2}$ Materials Synthesized by Sol-gel with Different Acid Catalysts". Journal of Non-Crystalline Solids. 354(2-9): 729-732.

[32] Galvan-Ruiz, M., Hernandez, J., Banos, L., Noriega- Montes J., Mario E. and Rodriguez (2009). "Characteristics of Calcium Carbonate, Calcium Oxide and Calcium Hydroxide as Starting Point to The Improvement of Lime for their Use In Construction". Journal of Materials in civil Engineering. 21(11): 694-698

[33] Tan Y. H., Abdullah M. O., Nolasco-Hipolito C. and TaufiqYap Y. H. (2015). "Waste Ostrich and Chicken Eggshells as Heterogeneous Base Catalyst for Biodiesel Production Fron Cooking Oil: Catalyst Characterization and Biodiesel Yield Performance". Journal of Applied Energy. 160:58-70. 